\title{
Contraceptive availability leads to increase in use in conflict-affected Democratic Republic of the Congo: evidence from cross-sectional cluster surveys, facility assessments and service statistics
}

Sara E. Casey ${ }^{1 *}$ and Martin Tshipamba ${ }^{2}$

\begin{abstract}
Background: Humanitarian assistance standards mandate specific attention to address the sexual and reproductive health (SRH) needs of conflict-affected populations. Despite these internationally recognised standards, access to SRH services is still often compromised in conflict settings. CARE in collaboration with the RAISE Initiative strengthened the Ministry of Health ( $\mathrm{MOH}$ ) to provide contraceptive services in Maniema province, Democratic Republic of the Congo. This study evaluated the effectiveness of this support for $\mathrm{MOH}$ health facility provision of contraception.

Methods: Cross-sectional surveys in $2008(n=607)$ and $2010(n=575)$ of women of reproductive age using a two-stage cluster sampling design were conducted in Kasongo health zone. Facility assessments were conducted to assess the capacity of supported government health facilities to provide contraceptive services in 2007 and 2010. Data on the numbers of clients who started a contraceptive method were also collected monthly from supported facilities for 2008-2014.

Results: Current use of any modern contraceptive method doubled from 3.1 to 5.9\% (adjusted OR 2.03 [95\%Cl 1.3-3.2]). Current use of long-acting and permanent methods (LAPM) increased from 0 to $1.7 \%(p<.001)$, an increase that was no longer significant after adjustment. All current users except a few condom users reported a health facility as the source of the method. The 2010 facility assessments found that most supported facilities had the capacity to provide short-acting and long-acting methods. Service statistics indicated that the percentage of clients who accepted a long-acting method at supported facilities increased from 8\% in 2008 to 83\% in $2014(p<.001)$.

Conclusions: This study demonstrated that contraceptive prevalence doubled between 2008 and 2010; service statistics indicate that utilization of long-acting methods continued to increase to a majority of new clients after 2010. Strengthening the health system to provide contraceptive services enabled individuals to exercise their right to prevent unintended pregnancies. These results suggest that demand for contraception, including long-acting methods, is present even in humanitarian settings, and that women will use them when they are available and of reasonable quality. It is critical that the humanitarian community ensure that such services are available to women affected by crises.
\end{abstract}

Keywords: Contraception, War, Democratic Republic of the Congo, Humanitarian aid, Reproductive health

\footnotetext{
* Correspondence: sec42@columbia.edu

${ }^{1}$ RAISE Initiative, Heilbrunn Department of Population and Family Health,

Mailman School of Public Health, Columbia University, 60 Haven Ave, New

York, NY 10032, USA

Full list of author information is available at the end of the article
}

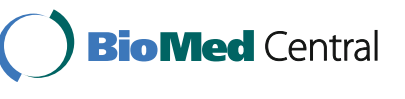

(c) The Author(s). 2017 Open Access This article is distributed under the terms of the Creative Commons Attribution 4.0 International License (http://creativecommons.org/licenses/by/4.0/), which permits unrestricted use, distribution, and reproduction in any medium, provided you give appropriate credit to the original author(s) and the source, provide a link to the Creative Commons license, and indicate if changes were made. The Creative Commons Public Domain Dedication waiver (http://creativecommons.org/publicdomain/zero/1.0/) applies to the data made available in this article, unless otherwise stated. 


\section{Background}

Complex humanitarian emergencies caused by armed conflict devastate already weak national health systems through the destruction of health facilities and flight of trained health workers [1]. Women living in conflict and post-conflict settings may face many sexual and reproductive health (SRH) concerns including high risk of mortality or morbidity due to pregnancy-related causes, unintended or unwanted pregnancy due to lack of information or access to contraceptive services, complications of unsafe abortions, gender-based violence and sexually transmitted infections including HIV $[2,3]$. The ten countries with the highest maternal mortality ratios in the world are affected by, or emerging from, war; these countries are also characterized by low contraceptive prevalence [4, 5]. Minimum standards of humanitarian assistance now recognize this increased risk and require attention to the SRH needs of the population [6]. Despite this, the availability of contraceptive services and information is still limited in humanitarian settings $[7,8]$ although demand for birth spacing or limiting exists in conflictaffected populations [9]. Few humanitarian organizations have prioritized contraception, especially long-acting and permanent methods, while SRH agencies rarely work in humanitarian settings $[2,8]$. When such services are available in humanitarian settings, they often are limited to short-acting methods [10-12].

Implementing comprehensive contraceptive services reduces the number of maternal deaths, particularly in countries with low contraceptive prevalence [13]. Maternal mortality and contraceptive prevalence have a strong negative correlation indicating that contraceptive services are a key intervention to prevent maternal mortality [13, 14]. According to the Countdown to 2015 for Maternal, Newborn and Child Survival, a reduction in maternal mortality and morbidity requires, among other changes, increased coverage of comprehensive contraceptive services $[15,16]$. To address personal preferences and respond to changing clinical needs over the life course, a broad range of methods is an essential component of good contraceptive programming [17-20]. Previous research documents that when contraceptive method choice expands, prevalence usually increases [21, 22] perhaps because it provides more options or greater ability to meet women's and couples' individual needs; this appears to be true even in humanitarian settings [23].

\section{Context and program description}

Nearly two decades of conflict and instability in eastern Democratic Republic of the Congo (DRC) have resulted in a compromised health system. Between 1998 and 2004, the conflict led to an estimated 3.9 million excess deaths [24]; the crude mortality rate was more than $70 \%$ higher than pre-war levels [25]. DRC has the sixth highest maternal mortality ratio in the world at 730 maternal deaths per 100,000 live births and a lifetime risk of maternal death of one in 23 [5]. The World Health Organization (WHO) determined that DRC made 'insufficient progress' towards achieving the fifth millennium development goal of improving maternal health [5]. For example, the DRC government contributes less than $1 \%$ of the cost of procuring contraceptives compared to $1-60 \%$ among other African countries [26, 27]. An index measuring the efforts of national contraceptive programs ranked DRC among the ten lowest performing countries in the world [28]. Modern contraceptive prevalence remains low at $7.8 \%$ in 2013, a small increase from 2007 (5.8\%) [29, 30]. Since 2012, the DRC government has made a greater commitment to contraceptive services; however, this has yet to diffuse to the provincial level, especially the conflict-affected eastern provinces [26].

Kasongo, in southern Maniema province, was heavily affected by the conflict in the late 1990s and early 2000 s and subsequent population displacement. The conflict exacerbated Kasongo's already substantial isolation by halting river and railroad traffic; the poor roads fell further into disrepair. CARE International began supporting Ministry of Health $(\mathrm{MOH})$ health services in Kasongo health zone in 2002, including limited contraceptive services: short-acting methods in all government health facilities and IUDs in two facilities beginning in 2004. According to current DRC MOH policy, health centres are mandated to provide all short- and longacting reversible methods while referral hospitals are expected to also provide permanent methods. In late 2007, CARE partnered with the Reproductive Health Access, Information and Services in Emergencies (RAISE) Initiative [31] to improve SRH services in the referral hospital and all 21 government health centers in Kasongo health zone. The initial focus of the program was on improving emergency obstetric care; short and long-acting reversible contraceptive methods were reinforced or introduced in the 22 government health facilities in mid2009. Tubal ligation was available at the hospital, primarily conducted during caesarean sections, although it was not as strongly reinforced as other methods; vasectomy was not available.

According to Bruce's quality of care framework, essential elements of good quality contraceptive services include clinical competence of providers, counselling skills including the information given to clients, interpersonal skills, support for continuation of method use and integration with other health services [17]. All CARE support was coordinated with the $\mathrm{MOH}$ and included these essential components: competency-based clinical training for providers, training on contraceptive counselling, provision of essential equipment and supplies and monitoring and 
evaluation. Mechanisms to improve continuation of method use and follow-up of short-acting method users were put in place. In addition, support was provided to the $\mathrm{MOH}$ to improve supply chain management, and revise contraceptive services registers to collect relevant data. In 2011, CARE's program shifted to focus on quality improvement and provided more in-depth support for contraceptive services in a smaller number of facilities (nine) in Kasongo, due to funding limitations [32].

All CARE support was coordinated through the $\mathrm{MOH}$ thus strengthening the health system, an important component of post-conflict recovery [1]. Health system strengthening is a long term process; for example, improving the $\mathrm{MOH}$ logistics system took time. The program focused first on establishing good quality contraceptive services, and less emphasis was placed on community education and outreach activities to avoid increasing demand for contraception before services were in place. Greater emphasis was appropriately placed on community education after 2010 when CARE established more systematic supervision and support of community educators, established expectations and regularly discussed challenges they faced and how to overcome them. Throughout the program, CARE worked closely with the $\mathrm{MOH}$ zonal team to strengthen their capacity to provide supportive supervision at the facilities in their health zone. For example, CARE and $\mathrm{MOH}$ supervisors worked with providers to identify weaknesses in service provision and jointly develop plans to address them. Together, they improved training on counseling with adaptations from the Population Council's Balanced counseling strategy and the World Health Organization's Decision-making tool for family planning clients and providers which use a series of job aids and an algorithm to promote unbiased contraceptive counseling [33, 34].

Few data are available to guide the effective provision of contraceptive services in conflict-affected settings, and the challenges to collecting data in these settings are well-recognised $[35,36]$. In this paper, we discuss the results of cross-sectional population-based surveys, facility assessments conducted in 2007 and 2010 and monthly service statistics to evaluate the effectiveness of the health facility provision of contraception, by the $\mathrm{MOH}$ with CARE support, in Kasongo health zone.

\section{Methods}

\section{Survey design \& sample}

Two cross-sectional population-based surveys were conducted in Kasongo health zone in February 2008 and October/November 2010. A two-stage cluster sampling design was used to ensure representation of the health zone population. Sampling was based on a $95 \%$ confidence interval and 50\% contraceptive prevalence, the most conservative estimate which requires the largest sample size [37]. Anticipating an $80 \%$ response rate, a total of 625 households was selected in 2008 to achieve the required sample of 500 women; in 2010, expecting a response rate similar to the $97 \%$ achieved in 2008,575 households were selected. Using $\mathrm{MOH}$ population estimates for villages in the catchment areas of each health facility, 25 clusters were selected using probability proportional to size. Within each cluster, 25 (2008) or 23 (2010) households were systematically selected using one of two methods. In larger villages, the study team randomly chose a direction from the center of the village, randomly selected the starting household from the first ten houses in that direction, and then systematically selected every tenth house until they reached the edge of the village. In villages with less than 250 households, the total number was divided by the desired number of households to determine the sampling interval; a random starting point was selected and then every $\mathrm{n}^{\text {th }}$ household based on this sampling interval. In 2008, after selection of the 25 clusters, two clusters were found to be inaccessible due to poor roads impassable because of rain; therefore, two additional clusters were selected. One woman of reproductive age (15-49 years) was selected from all eligible women in each household using a Kish table [38].

\section{Procedures}

The survey questionnaire was adapted from the US Centers for Disease Control and Prevention's Reproductive Health Assessment Toolkit for Conflict Affected Women [39]. The same questionnaire was used in 2008 and 2010 with minor adaptations to enhance clarity. The questionnaire covered multiple SRH topics; this paper focuses on the results related to contraception. The original CDC questionnaire was translated into French; all adaptations were made in the French version which was then translated into Congolese Swahili. The Swahili translation was subsequently reviewed and revised by the baseline survey team.

All interviewers (22 in 2008 and 16 in 2010) were female to ensure cultural appropriateness while increasing the likelihood of accurate data collection on SRH topics. During a ten-day training for supervisors and interviewers, they learned SRH terminology and survey techniques, and participated in practical exercises to assure mastery of material. The questionnaire was piloted in villages that were not included in the survey samples.

\section{Statistical analysis}

Data were double-entered into CSPro Version 3.1 and subsequently exported to PASW (SPSS) Version 21 for cleaning and analysis. Data were weighted according to the number of eligible women of reproductive age in the household. Logistic regression was used to calculate 
odds ratios (ORs) and 95\% confidence intervals to compare contraception outcomes in 2008 and 2010, adjusting for differences in the distribution of key population demographics which may influence contraception outcomes (education and religion in this study).

Modern contraceptive methods are defined as oral contraceptive pills, injectables, male and female condoms, implants, IUDs, tubal ligation, vasectomy. Long-acting methods are defined as implant and IUD; permanent methods as tubal ligation and vasectomy. Results are reported for all women, married and unmarried, unless otherwise specified. Regression models excluding unmarried women who were not sexually active produced the same results as those including all women.

\section{Facility assessments}

To demonstrate that the supported health facilities had the capacity to provide the contraceptive services asked about in the survey, facility assessments were conducted in November/December 2007 and in July 2010 in 22 supported government health facilities. The trained assessment teams, which included $\mathrm{MOH}$ and CARE staff, used a standardized tool adapted from the Averting Maternal Death and Disability Program's emergency obstetric care needs assessment tool [40]. The methods, including interviews with facility staff, a room by room inventory of equipment and supplies and clinical records review, evaluated physical infrastructure, human resources, infection prevention procedures and SRH service readiness [41]. Contraceptive service readiness was defined as the availability and functionality of essential equipment and supplies and presence of trained providers.

\section{Service statistics}

Data on the numbers of clients who started a contraceptive method were collected monthly from the 22 government facilities from January 2008 through May 2011, and from nine government facilities June 2011 through December 2014.

\section{Ethical considerations}

All interviewed participants were asked to give oral informed consent; names were not recorded to preserve anonymity. Parental consent for women aged 15-17 was waived since this study met the criteria for minimal risk. Ethical approvals for the study were obtained from the Institutional Review Board of the Mailman School of Public Health, Columbia University and the Congolese $\mathrm{MOH}$.

\section{Results}

Surveys

The women in our 2008 and 2010 samples (607 and 564 respondents respectively) were similar with respect to age, marital or cohabitation status, ability to read, number of living children and having experienced an unwanted pregnancy (Table 1). Most respondents were under 35 years old, married, unable to read well or at all and had three or more children. Nearly all women reported being a local resident (rather than currently displaced). More women reported being Muslim in $2010(73.1 \%)$ than in 2008 (66.4\%), while fewer reported being Protestant in 2010 (3.7\%) compared to $2008(8.0 \%, p<.001)$. Although the percentage who reported being able to read easily remained the same, more women reported having at least some secondary education in $2010(23.0 \%)$ than in $2008(17.9 \%, p=.04)$.

Significant increases in four categories of knowledge and use of modern contraception between 2008 and 2010 are shown in Table 2. When asked to name any modern contraceptive method, $28.0 \%$ spontaneously mentioned at least one modern method in 2008 compared to $49.5 \%$ in $2010(p<.001)$. In addition, $6.0 \%$ of women in 2008 spontaneously named a long-acting or permanent method (LAPM) while $10.3 \%$ of women did so in $2010(p=.001)$. The percentage who reported having received instruction on how to use a modern method increased from $28.8 \%$ in 2008 to $44.5 \%$ in 2010 $(p<.001)$, while those who reported having been instructed how to use an LAPM nearly doubled, from $7.9 \%$ in 2008 to $16.7 \%$ in $2010(p<.001)$.

Ever use of any modern method increased from 11.5 to $18.8 \%(p<.001)$, while ever use of an LAPM increased from 0.3 to $2.0 \%(p=.02)$. Current use of a modern contraceptive method doubled from $3.1 \%$ in 2008 to $5.9 \%$ in $2010(p=.004)$, while use of any LAPM increased from 0 in 2008 to $1.7 \%$ in $2010(p<.001)$. The increase in current use of any modern method persisted when adjusted for religion and education (adjusted OR 2.03 [95\% CI 1.3-3.2]). However, the increase in current use of a LAPM was no longer significant after adjusting for these socio-demographic variables. Increases in knowledge of LAPM (adjusted OR 1.87 [95\% CI 1.32.6]) and having received instruction on how to use LAPM (adjusted OR 2.2 [95\% CI 1.7-3.0]) persisted after adjustment. An adjusted model which excluded unmarried women who were not sexually active produced the same results as above.

Among women reporting current use of a modern contraceptive method in 2010, $81.1 \%$ reported a health facility as the source of the method while $19.0 \%$ of respondents, all of them condom users, reported a pharmacy or market as their source.

\section{Facility assessments}

In 2007, all health facilities reported having provided pills and injectables in the three months prior to the assessment and 20 had the methods currently in stock; two reported providing IUDs and had them in stock, 
Table 1 Socio-demographic characteristics of the populations sampled in 2008 and 2010

\begin{tabular}{|c|c|c|c|}
\hline & $2008(N=1006,607)^{a}$ & $2010(N=1007,564)^{a}$ & $p$-value \\
\hline Age (years) & & & $p=.088$ \\
\hline $15-24$ & $42.9 \%(264)$ & $38.1 \%(215)$ & \\
\hline $25-34$ & $31.4 \%(187)$ & $33.6 \%(193)$ & \\
\hline $35-49$ & $25.7 \%(155)$ & $28.3 \%(156)$ & \\
\hline Mean age (SD), years & $28.0(9.2)$ & $28.8(9.6)$ & $p=.05$ \\
\hline Marital status & & & $p=.099$ \\
\hline Married \& living with husband & $82.8 \%(517)$ & $82.5 \%(486)$ & \\
\hline Married \& not living with husband & $5.7 \%(38)$ & $7.8 \%(34)$ & \\
\hline Not married, living with partner & $0.7 \%(3)$ & $0.3 \%(2)$ & \\
\hline Not married, not living with partner & $10.8 \%(49)$ & $9.3 \%(42)$ & \\
\hline Number of living children & & & $p=.416$ \\
\hline 0 & $18.3 \%(96)$ & $16.6 \%(77)$ & \\
\hline $1-2$ & $29.5 \%(199)$ & $27.6 \%(168)$ & \\
\hline $3-4$ & $27.7 \%(158)$ & $29.0 \%(164)$ & \\
\hline $5+$ & $24.5 \%(153)$ & $28.3 \%(155)$ & \\
\hline Religion & & & $p<.001$ \\
\hline Muslim & $66.4 \%(394)$ & $73.1 \%(404)$ & \\
\hline Catholic & $18.8 \%(115)$ & $18.8 \%(107)$ & \\
\hline Protestant & $8.0 \%(55)$ & $3.7 \%(23)$ & \\
\hline Pentecostal/Evangelical & $4.5 \%(29)$ & $3.1 \%(24)$ & \\
\hline Other & $2.4 \%(14)$ & $1.4 \%(6)$ & \\
\hline Formal education & & & $p=.037$ \\
\hline None & $35.6 \%(204)$ & $34.1 \%(205)$ & \\
\hline Did not complete primary school & $35.6 \%(224)$ & $32.4 \%(187)$ & \\
\hline Completed primary school & $10.9 \%(60)$ & $10.5 \%(59)$ & \\
\hline At least some secondary education & $17.9 \%(119)$ & $23.0 \%(113)$ & \\
\hline Self-reported ability to read & & & $p=.307$ \\
\hline With difficulty or not at all & $76.3 \%(453)$ & $74.3 \%(434)$ & \\
\hline Easily & $23.7 \%(154)$ & $25.7 \%(130)$ & \\
\hline Number of lifetime pregnancies & & & $p=.55$ \\
\hline 0 & $12.1 \%(57)$ & $11.3 \%(54)$ & \\
\hline $1-2$ & $21.5 \%(145)$ & $22.3 \%(130)$ & \\
\hline $3-4$ & $21.0 \%(129)$ & $22.1 \%(128)$ & \\
\hline $5-9$ & $34.7 \%(217)$ & $31.9 \%(188)$ & \\
\hline $10+$ & $10.7 \%(59)$ & $12.3 \%(64)$ & \\
\hline Reported an unwanted pregnancy & & & $p=.419$ \\
\hline No & $73.9 \%(443)$ & $75.6 \%(441)$ & \\
\hline Yes & $26.1 \%(163)$ & $24.4 \%(123)$ & \\
\hline
\end{tabular}

Data are $\%$ of column weighted base (absolute counts), unless indicated. Bases are smaller for some variables due to missing data. Missing data are less than $0.5 \%$ for all variables

${ }^{\mathrm{a}} \mathrm{N}=$ weighted and unweighted base

while no facility had implants or any staff trained to provide them (Table 3). In 2010, nearly all facilities had provided pills, injectables and implants in the three months prior to the assessment and had them in stock, while seven facilities had provided IUDs and nine had them in stock. All facilities had staff trained to insert and remove implants and 19 had staff trained to insert and remove IUDs in 2010. 
Table 2 Reported knowledge and use of modern contraceptive methods in 2008 and 2010

\begin{tabular}{|c|c|c|c|c|c|c|}
\hline & $\begin{array}{l}2008(95 \% \mathrm{Cl}) \\
(N=607)^{\mathrm{a}}\end{array}$ & $\begin{array}{l}2010(95 \% \mathrm{Cl}) \\
(N=564)^{\mathrm{a}}\end{array}$ & $p$-value & $\begin{array}{l}\text { Unadjusted OR }(95 \% \mathrm{Cl}) \\
(N=1171)\end{array}$ & $\begin{array}{l}\text { Adjusted OR }(95 \% \mathrm{Cl})^{\mathrm{b}} \\
(\mathrm{N}=1171)\end{array}$ & $\begin{array}{l}p \text {-value, } \\
\text { Adjusted OR }\end{array}$ \\
\hline \multicolumn{7}{|c|}{ Spontaneous knowledge of modern contraceptive methods } \\
\hline Any modern method & $28.0 \%(25.1-30.7)$ & $49.4 \%(46.3-52.6)$ & $p<.001$ & $2.5(2.1-3.0)$ & $2.7(2.2-3.2)$ & $p<0.001$ \\
\hline Any LAPM & $6.0 \%(4.4-7.6)$ & $10.3 \%(8.5-12.2)$ & $p=.001$ & $1.8(1.3-2.5)$ & $1.87(1.3-2.6)$ & $p<0.001$ \\
\hline \multicolumn{7}{|c|}{ Reported prior instruction on how to use modern contraceptive method } \\
\hline Any modern method & $28.8 \%(26.2-31.7)$ & $44.5 \%(41.4-47.5)$ & $p<.001$ & $1.98(1.6-2.4)$ & $1.98(1.6-2.4)$ & $p<0.001$ \\
\hline Any LAPM ${ }^{c}$ & $7.9 \%(6.2-9.5)$ & $16.7 \%(14.5-19.1)$ & $p<.001$ & $2.3(1.8-3.1)$ & $2.2(1.7-3.0)$ & $p<0.001$ \\
\hline \multicolumn{7}{|c|}{ Reported ever use of modern contraceptive method } \\
\hline Any modern method & $11.5 \%(9.6-13.5)$ & $18.8 \%(16.4-21.3)$ & $p<.001$ & $1.8(1.3-2.8)$ & $1.8(1.4-2.4)$ & $p<0.001$ \\
\hline Any LAPM ${ }^{c}$ & $0.3 \%(0.0-0.7)$ & $2.0 \%(1.1-2.8)$ & $p=.02$ & & & \\
\hline \multicolumn{7}{|c|}{ Reported current use of modern contraceptive method } \\
\hline Any modern method & $3.1 \%(2.0-4.2)$ & $5.9 \%(4.5-7.4)$ & $p=.004$ & $1.96(1.3-3.0)$ & $2.03(1.3-3.2)$ & $p=.002$ \\
\hline Any LAPM ${ }^{c}$ & $0 \%$ & $1.7 \%(1.0-2.6)$ & $p<.001$ & & & \\
\hline
\end{tabular}

${ }^{\mathrm{a}} \mathrm{N}=$ unweighted base

${ }^{\mathrm{b}}$ Adjusted for religion and education

'Long-acting and permanent methods (LAPM) are IUD, implant, tubal ligation and vasectomy

\section{Service statistics}

From January 2008 to May 2011, the 22 facilities provided contraceptive methods to 9939 clients starting a method, including 2,202 who selected a LAPM (Fig. 1). The percentage of clients who accepted a LAPM increased from $7.9 \%$ in 2008 to $30.1 \%$ in 2010 ( $p<.001)$. From June 2011 to December 2014, 17,872 clients started a method at nine CARE-supported facilities, 13,708 of whom accepted a LAPM. The percentage of clients who accepted a LAPM increased dramatically to $82.9 \%$ in $2014(p<.001)$. The method mix changed from dominance of short-acting methods in 2008-2010 to long-acting methods in 2012-2014; use of tubal ligation did not change (Fig. 2).

\section{Discussion}

Our results demonstrate that increasing contraceptive use, even in remote conflict-affected settings, is feasible. Kasongo is an isolated, inaccessible region that was highly affected by the conflict of the late 1990s/early 2000 s in eastern DRC. Knowledge of contraception was very low in 2008, with barely a quarter of respondents able to spontaneously name a modern contraceptive method, lower than the $70 \%$ found in rural areas nationally in the 2007 Demographic and Health Survey (DHS) [30]; only half were able to do so in 2010. Modern contraceptive prevalence in 2008 in Kasongo (3.1\%) was similar to that found in rural DRC $(3.3 \%)$ in the 2007 DHS. While contraceptive use remained low overall, prevalence nevertheless doubled from 2008 levels. The contraceptive prevalence of $5.9 \%$ found in this study was higher than the $3.6 \%$ found in rural areas of DRC in the 2010 MICS survey [42], as was the LAPM prevalence $(1.7 \%$ versus $1.0 \%)$. We believe that the CARE program was the source of contraceptive method for most respondents who reported current use in 2010 as all except some condom users reported a public health facility as their source. This program supported contraceptive services at all of the public health facilities in the health zone; the 2010 facility assessments confirmed that contraceptive methods were available at all of these facilities; increasing numbers of clients accepted a method at these facilities during this time period. In addition, interviews with the $\mathrm{MOH}$ Health Zone Medical Officer indicated that no private facilities provided contraceptive methods, aside from condoms, in Kasongo at the time. Our results suggest that demand for contraception, including long-acting methods, is present even

Table 3 Number of facilities providing contraceptive services in 2007 and 2010

\begin{tabular}{|c|c|c|c|c|c|c|}
\hline & \multicolumn{3}{|l|}{$2007(n=21)$} & \multicolumn{3}{|l|}{$2010(n=22)$} \\
\hline & $\begin{array}{l}\text { Provided in previous } \\
3 \text { months (self-reported) }\end{array}$ & $\begin{array}{l}\text { Method currently } \\
\text { in stock }\end{array}$ & $\begin{array}{l}\text { At least one staff } \\
\text { trained to provide }\end{array}$ & $\begin{array}{l}\text { Provided in previous } \\
3 \text { months (self-reported) }\end{array}$ & $\begin{array}{l}\text { Method currently } \\
\text { in stock }\end{array}$ & $\begin{array}{l}\text { At least one staff } \\
\text { trained to provide }\end{array}$ \\
\hline Pills & 21 & 20 & 21 & 22 & 21 & 22 \\
\hline Injectables & 21 & 20 & 21 & 20 & 20 & 22 \\
\hline IUDs & 2 & 2 & 2 & 7 & 9 & 19 \\
\hline Implants & 0 & 0 & 0 & 21 & 21 & 22 \\
\hline
\end{tabular}




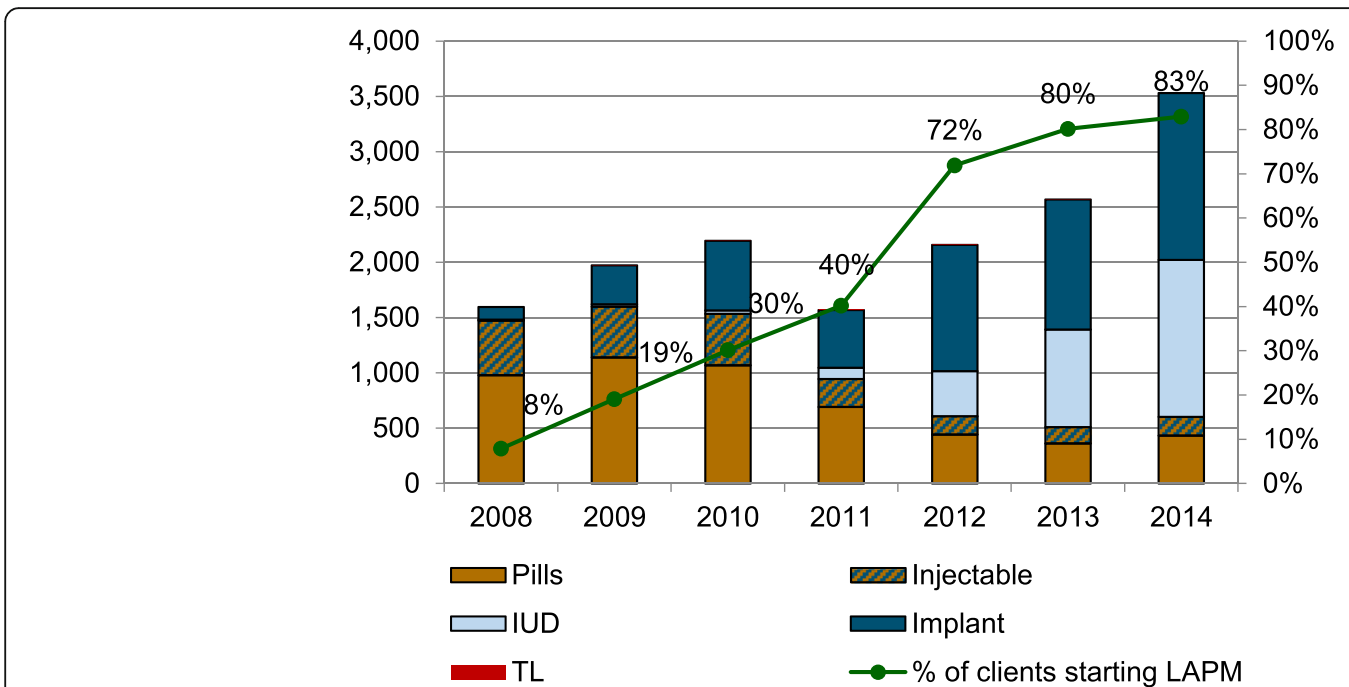

Fig. 1 Number of clients who started contraceptive methods and percentage who started LAPM in health facilities supported by CARE in Kasongo, DRC ( $n=22$, 2008-May 2011 and $n=9$, June 2011-2014)

in humanitarian settings, and that women will use them when they are available and of reasonable quality.

While population-level survey data are important, people only use services that are available and of reasonable quality. Long-acting reversible contraceptives were new in Kasongo when they were introduced via this program, as demonstrated by the low knowledge of these methods and their near absence in facilities in 2008. The facility assessments found that long-acting methods were available in the supported facilities by 2010, and nearly all facilities had staff trained to provide both short- and long-acting methods. While all but one facility had implants in stock and reported providing implants in the three months prior to the 2010 assessments, just under half had IUDs in stock and had provided IUDs. While use of long-acting methods increased only slowly in the first two years of service provision, the service statistics show a dramatic change after 2010. Program adjustments were made to improve quality which likely contributed to the increased numbers of clients after 2010 . The proportion of clients accepting a long-acting method increased from $8 \%$ of new acceptors in 2008 to $30 \%$ in 2010 , and then to $84 \%$ in 2014 . Program data demonstrate a steady and sharp increase in implant acceptors, from 115 new acceptors in 2008 to over 600 in 2010 and more than 1,500 in 2014. IUD acceptors, on the other hand, increased at a much slower rate early in the program, from 11 new acceptors in 2008 to 31 in 2010 , and then to over 1,400 in 2014. This shift in method mix from dominance of short-acting methods to long-acting methods demonstrates that improving access to neglected methods, such as IUDs, is feasible. This study adds to the limited evidence that increasing method choice is associated with increased contraceptive use in isolated humanitarian settings.

These survey results led CARE to focus strongly on quality improvement in a smaller number of facilities in 2011: enhancing on-the-job training to improve counseling, address provider bias towards IUDs and ensure providers maintained clinical competency [32]. One barrier to the provision of LAPM, identified here and in similar programs, is limited provider competence [23, 43].
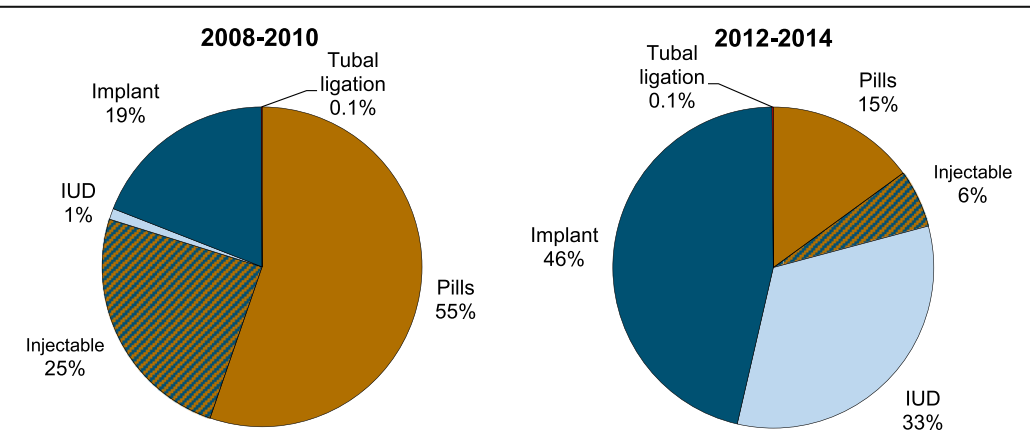

Fig. 2 Contraceptive method mix from 2008-2010 ( $n=22$ facilities) and 2012-2014 ( $n=9$ facilities), Kasongo, DRC 
While all facilities had providers trained to provide longacting methods, a potential reason for the slower increase in LAPM use from 2008-2010 could be related to provider confidence in their ability to provide these methods. Although efforts were made to ensure each provider had clinical practice during training, the low numbers of IUD acceptors, in particular, early in the program made it difficult for providers to maintain their skills or confidence in their skills, which may have discouraged them from offering these methods to clients. In response, supervisors carried anatomic pelvic models during supervision visits to permit providers to practice inserting IUDs under observation with a checklist which gave them greater confidence in their skills.

Other potential reasons for the initial limited increase in LAPM use from 2008-2010 may be bias against these methods, fear of side effects or misinformation regarding particular methods in the community [44]. To identify these potential barriers, CARE conducted a community analysis and developed education messages to address them. In addition to the program's network of community educators, local community groups and satisfied users also conducted education on contraception. This more routine engagement allowed CARE to more quickly respond to rumors and misinformation in the community.

These survey results were used to address challenges related to provider bias and competence as well as barriers at community level. The increasing numbers of contraceptive clients starting a method in the supported health facilities, the availability of contraceptives in the supported facilities and lack of alternative sources of contraceptive services in Kasongo health zone, the increase in knowledge of contraceptive methods and increased ever and current use of contraception suggest successful implementation of this program [45, 46]. Although a third survey was not conducted, the service statistics suggest that this program has resulted in increasing utilization of contraception, and particularly of long-acting methods. The data indicate that while clients are interested in long-acting methods, barriers to IUD use among the community and providers took longer to address. Although these results may not be generalizable to all humanitarian settings, organizations implementing contraceptive services in such settings may find them useful. The positive results took time to achieve but are more likely to be sustained as all program components were implemented in collaboration with the $\mathrm{MOH}$, including training, supervision and supplies management. Multi-year donor funding permitted this program to focus on quality improvement once the basic services were in place. Making good quality contraceptive services available was challenging and required sustained commitment, time and program adjustments, but was ultimately successful. It is important for other programs implementing contraceptive services in humanitarian settings to document how they achieved their success.

\section{Limitations}

Data were collected in two cross-sectional surveys in 2008 and 2010 rather than using control communities, a choice made for ethical reasons. In their absence, it is difficult to identify changes in contraceptive prevalence that would have occurred without this program. Villages that were inaccessible were excluded from the sampling frame which may have led to an overestimation of results. It was the perception of the interviewers that respondents were largely forthcoming during the interviews; nevertheless, as in all surveys, respondents may have modified their answers according to social norms or to their perceptions of interviewer expectations or experienced recall bias. Although DRC presents challenges common to many humanitarian settings, the results may not be generalizable to other humanitarian settings.

\section{Conclusion}

In conflict-affected countries, contraceptive availability is often limited to short-acting methods or none at all. This study demonstrated that contraceptive prevalence doubled between 2008 and 2010. Service statistics suggest that utilization of long-acting methods continued to increase to a majority of new clients after 2010, when provider skills and counseling improved and the methods became routinely available. Strengthening the health system to provide contraception enables individuals to exercise their right to prevent unintended pregnancies while improving the long-term sustainability of these services. Given true choice, when a range of methods was routinely available, women were able to choose the method that best served their needs, increasingly long-acting methods. This study demonstrates that even in remote and unstable settings like Kasongo, when good quality contraceptive services are in place, women will choose to use them. It is critical that the humanitarian community ensure that such services are available to women affected by crises.

\footnotetext{
Abbreviations

DRC: Democratic Republic of the Congo; IUD: Intra-uterine device; LAPM: Longacting or permanent method; $\mathrm{MOH}$ : Ministry of Health; OR: Odds ratio; RAISE Initiative: Reproductive Health Access, Information and Services in Emergencies; SRH: Sexual and reproductive health; WHO: World Health Organization
}

\section{Acknowledgments}

We thank the survey participants who shared their experiences as well as the data collection teams in 2007/2008 and 2010 who conducted the interviews and facility assessments for their enthusiasm and dedication. We also acknowledge the

valuable support and advice of Dr Therese McGinn throughout the process. 


\section{Funding}

CARE and the RAISE Initiative were funded by an anonymous private foundation. The funders had no role in study design, data collection and analysis, decision to publish, or preparation of the manuscript.

\section{Availability of data and materials}

The datasets generated and/or analysed during the current study are not publicly available because they were collected for programmatic use and not intended for other purposes but may be available from the corresponding author on reasonable request.

\section{Authors' contributions}

SEC participated in the study conception, design and implementation of the study; analyzed the data and drafted the manuscript. MT participated in the implementation of the study and provided feedback on the manuscript. Both authors reviewed and approved the final version of the manuscript, and had access to all the data. The corresponding author had final responsibility for the decision to submit for publication

\section{Competing interests}

The authors declare that they have no competing interests.

\section{Consent for publication}

Not applicable.

\section{Ethics approval and consent to participate}

CUMC IRB approval reference: AAAC4087.

\section{Author details}

${ }^{1}$ RAISE Initiative, Heilbrunn Department of Population and Family Health, Mailman School of Public Health, Columbia University, 60 Haven Ave, New York, NY 10032, USA. 'SAF-PAC Project, CARE, 65, Av.de la corniche, Quartier les Volcans, Goma, Nord Kivu, Democratic Republic of the Congo.

\section{Received: 23 June 2016 Accepted: 19 January 2017}

\section{Published online: 08 March 2017}

\section{References}

1. Kruk ME, Freedman LP, Anglin GA, Waldman RJ. Rebuilding health systems to improve health and promote statebuilding in post-conflict countries: a theoretical framework and research agenda. Soc Sci Med. 2010;70:89-97.

2. Austin J, Guy S, Lee-Jones L, McGinn T, Schlecht J. Reproductive health: a right for refugees and internally displaced persons. Reprod Health Matters. 2008;16:10-21

3. Glasier A, Gulmezoglu A, Schmid G, Moreno C, Van Look P. Sexual and reproductive health: a matter of life and death. Lancet. 2006;368:1595-607.

4. Alkema L, Kantorova V, Menozzi C, Biddlecom A. National, regional, and global rates and trends in contraceptive prevalence and unmet need for family planning between and 2015: a systematic and comprehensive analysis. Lancet. 1990;2013(381):1642-52.

5. WHO, UNICEF, UNFPA, World Bank. Trends in maternal mortality: 1990-2013. Estimates by WHO, UNICEF, UNFPA, The world bank and the UN population division. Geneva: WHO; 2014. http://apps.who.int/iris/bitstream/10665/ 112682/2/9789241507226_eng.pdf, Accessed 26 Oct 2016.

6. Sphere Project: Sphere Project: Humanitarian Charter and Minimum Standards in Humanitarian Response. 3rd edn; 2011. http://www. sphereproject.org/handbook/. Accessed 26 Oct 2016.

7. Casey SE, Chynoweth SK, Cornier N, Gallagher MC, Wheeler EE. Progress and gaps in reproductive health services in three humanitarian settings: mixedmethods case studies. Confl Heal. 2015;9:S3.

8. Chynoweth SK. Advancing reproductive health on the humanitarian agenda: the 2012-2014 global review. Confl Heal. 2015;9:11.

9. McGinn T, Austin J, Anfinson K, Amsalu R, Casey SE, Fadulalmula SI, Langston A, Lee-Jones L, Meyers J, Mubiru FK, et al. Family planning in conflict: results of cross-sectional baseline surveys in three African countries. Confl Heal. 2011:5:11.

10. Howard N, Kollie S, Souare Y, von Roenne A, Blankhart D, Newey C, Chen $\mathrm{MI}$, Borchert M. Reproductive health services for refugees by refugees in Guinea I: family planning. Confl Heal. 2008;2:12.

11. Huber D, Saeedi N, Samadi AK. Achieving success with family planning in rural Afghanistan. Bull World Health Organ. 2010;88:227-31.
12. Mullany LC, Lee TJ, Yone L, Lee Cl, Teela KC, Paw P, Shwe Oo EK, Maung C, Kuiper H, Masenior NF, Beyrer C. Impact of community-based maternal health workers on coverage of essential maternal health interventions among internally displaced communities in Eastern Burma: The MOM Project. PLoS Med. 2010;7:e1000317.

13. Prata N, Sreenivas A, Vahidnia F, Potts M. Saving maternal lives in resourcepoor settings: facing reality. Health Policy. 2009;89:131-48.

14. Ahmed S, Li Q, Liu L, Tsui AO. Maternal deaths averted by contraceptive use: an analysis of 172 countries. Lancet. 2012;380:111-25.

15. Bhutta ZA, Chopra M, Axelson H, Berman P, Boerma T, Bryce J, Bustreo F, Cavagnero E, Cometto G, Daelmans B, et al. Countdown todecade report (2000-10): taking stock of maternal, newborn, and child survival. Lancet. 2015:2010(375):2032-44

16. Requejo JH, Bryce J, Barros AJD, Berman P, Bhutta Z, Chopra M, Daelmans B, de Francisco A, Lawn J, Maliqi B, et al. Countdown to and beyond: fulfilling the health agenda for women and children. Lancet. 2015;2015(385):466-76.

17. Bruce J. Fundamental elements of the quality of care: a simple framework. Stud Fam Plann. 1990;21:61-91.

18. Cleland J, Bernstein S, Ezeh A, Faundes A, Glasier A, Innis J. Family planning: the unfinished agenda. Lancet. 2006;368:1810-27.

19. Prata N. Making family planning accessible in resource-poor settings. Philos Trans R Soc Lond B Biol Sci. 2009;364:3093-9.

20. Snow RC, Laski L, Mutumba M. Sexual and reproductive health: progress and outstanding needs. Glob Public Health. 2015;10:149-73.

21. Ross J, Hardee K, Mumford E, Eid S. Contraceptive method choice in developing countries. Int Fam Plan Perspect. 2002;28:32-40.

22. Ross J, Stover J. Use of modern contraception increases when more methods become available: analysis of evidence from 1982-2009. Glob Health Sci Pract. 2013;1:203-12.

23. Casey SE, McNab SE, Tanton C, Odong J, Testa AC, Lee-Jones L. Availability of long-acting and permanent family-planning methods leads to increase in use in conflict-affected northern Uganda: evidence from cross-sectional baseline and endline cluster surveys. Glob Public Health. 2013;8:284-97.

24. Coghlan B, Brennan R, Ngoy P, Dofara D, Otto B, Clements M, Stewart T. Mortality in the Democratic Republic of the Congo: a nationwide survey. Lancet. 2006;367:44-51.

25. Coghlan B, Ngoy P, Mulumba F, Hardy C, Bemo VN, Stewart T, Lewis J, Brennan RJ. Update on mortality in the Democratic Republic of Congo: results from a third nationwide survey. Disaster Med Public Health Prep. 2009;3:88-96.

26. Mukaba T, Binanga A, Fohl S, Bertrand JT. Family planning policy environment in the Democratic Republic of the Congo: levers of positive change and prospects for sustainability. Glob Health Sci Pract. 2015;3:163-73.

27. USAID DELIVER Project. Measuring contraceptive security indicators in 2011. Arlington: USAID DELIVER Project, Task Order 4; 2012. http://deliver.jsi.com/dlvr_ content/resources/allpubs/guidelines/MeasCSIndi_2011.pdf, Accessed 26 Oct 2016.

28. Ross J, Smith E. The family planning effort index: 1999, 2004, and 2009. Washington: Futures Group; 2010. http://www.healthpolicyinitiative.com/ Publications/Documents/1110_1_FP_Effort_Index_1999_2004_2009_ FINAL_05_08_10_acc.pdf, Accessed 26 Oct 2016.

29. Ministère du Plan et Suivi de la Mise en oeuvre de la Révolution de la Modernité, Ministère de la Santé Publique, ICF International. Enquête Démographique et de Santé en République Démocratique du Congo 2013 2014. Rockville; 2014. https://dhsprogram.com/pubs/pdf/FR300/FR300.pdf. Accessed 26 Oct 2016

30. Ministère du Plan, Macro International. Enquête Démographique et de Santé, République Démocratique du Congo 2007. Calverton: Ministère du Plan et Macro International; 2008. https://dhsprogram.com/pubs/pdf/FR208/ FR208.pdf. Accessed 26 Oct 2016

31. RAISE Initiative. www.raiseinitiative.org. Accessed 26 Oct 2016.

32. Ward D, Rattan J, Nzau J, Giri K. Delivering high-quality family planning services in crisis-affected settings I: program implementation. Glob Health Sci Pract. 2015;3:14-24.

33. Léon F, Vernon R, Martin A, Bruce L. The balanced counseling strategy: a toolkit for family planning service providers. Washington, DC: Population Council; 2008. http://www.popcouncil.org/uploads/pdfs/poster/frontiers/ Manuals/BCS/BCS_UsersGuide.pdf, Accessed 26 Oct 2016.

34. World Health Organization. INFO Project at the Johns Hopkins Bloomberg School of Public Health/Center for Communication Programs: decisionmaking tool for family planning clients and providers. Geneva: WHO; 2005. http://apps.who.int/iris/bitstream/10665/43225/2/9241593229_eng.pdf, Accessed 26 Oct 2016 
35. Ford N, Mills E, Zachariah R, Upshur R. Ethics of conducting research in conflict settings. Confl Heal. 2009;3:7.

36. Thoms O, Ron J. Public health, conflict and human rights: toward a collaborative research agenda. Confl Heal. 2007;1:11.

37. Bennett S, Woods T, Liyanage WM, Smith DL. A simplified general method for cluster-sample surveys of health in developing countries. World Health Stat Q. 1991;44:98-106.

38. Kish $\mathrm{L}$. A procedure for objective respondent selection within the household. J Am Stat Assoc. 1949;44:380-7.

39. U.S. Centers for Disease Control and Prevention. Reproductive health assessment toolkit for conflict-affected women. Atlanta: U.S. Centers for Disease Control and Prevention; 2007. http://www.cdc.gov/ reproductivehealth/global/tools/crisissituations.htm, Accessed 26 Oct 2016.

40. Averting Maternal Death and Disability Program (AMDD): EmOC Needs Assessment Toolkit. https://www.mailman.columbia.edu/research/avertingmaternal-death-and-disability-amdd/toolkit. Accessed 26 Oct 2016.

41. Gill Z, Bailey P, Waxman R, Smith JB. A tool for assessing readiness in emergency obstetric care: The room-by-room walk-through. Int J Gynecol Obstet. 2005;89:191-199.

42. Ministere du Plan, Institut National de la Statistique, UNICEF. Enquête par Grappes à Indicateurs Multiples en République Démocratique du Congo (MICS-RDC 2010), Rapport Final. Kinshasa; 2011. http://www.childinfo.org/ files/MICS-RDC_2010_Final_Report_FR.pdf.

43. Casey S, Mitchell K, Amisi I, Haliza M, Aveledi B, Kalenga P, Austin J. Use of facility assessment data to improve reproductive health service delivery in the Democratic Republic of the Congo. Confl Heal. 2009:3:12.

44. Campbell M, Sahin-Hodoglugil NN, Potts M. Barriers to fertility regulation: a review of the literature. Stud Fam Plan. 2006;37:87-98.

45. Habicht JP, Victora CG, Vaughan JP. Evaluation designs for adequacy, plausibility and probability of public health programme performance and impact. Int J Epidemiol. 1999;28:10-8.

46. Shelton JD. Evidence-based public health: not only whether it works, but how it can be made to work practicably at scale. Glob Health Sci Pract. 2014;2:253-8.

\section{Submit your next manuscript to BioMed Central and we will help you at every step:}

- We accept pre-submission inquiries

- Our selector tool helps you to find the most relevant journal

- We provide round the clock customer support

- Convenient online submission

- Thorough peer review

- Inclusion in PubMed and all major indexing services

- Maximum visibility for your research

Submit your manuscript at www.biomedcentral.com/submit

) Biomed Central 